\title{
Description of Concrete Creep under Time-Varying Stress Using Parallel Creep Curve
}

\author{
Yeong-Seong Park, ${ }^{1}$ Yong-Hak Lee, ${ }^{1}$ and Youngwhan Lee ${ }^{2}$ \\ ${ }^{1}$ Department of Civil Engineering, Konkuk University, 120 Neungdong-ro, Gwangjin-gu, Seoul 143-701, Republic of Korea \\ ${ }^{2}$ Department of MOT, Konkuk University, 120 Neungdong-ro, Gwangjin-gu, Seoul 143-701, Republic of Korea \\ Correspondence should be addressed to Yong-Hak Lee; leeyo@konkuk.ac.kr
}

Received 2 September 2015; Accepted 17 January 2016

Academic Editor: Jun Liu

Copyright (c) 2016 Yeong-Seong Park et al. This is an open access article distributed under the Creative Commons Attribution License, which permits unrestricted use, distribution, and reproduction in any medium, provided the original work is properly cited.

\begin{abstract}
An incremental format of creep model was presented to take account of the development of concrete creep due to loading at different ages. The formulation was attained by introducing a horizontal parallel assumption of creep curves and combining it with the vertical parallel creep curve of the rate of creep method to remedy the disadvantage of the rate of creep method that significantly underestimates the amount of creep strain, regardless of its simple format. Two creep curves were combined by introducing an ageing parameter whose value was obtained from two sets of time-dependent laboratory experiments on cylindrical specimens. The presented creep description takes the advantage that a single creep curve due to the initial loading describes the entire development of creep under the persistent change of creep-causing stress. Further, the creep formulation takes advantage of being consistent with the incremental format of age-dependent constitutive formulation. The performance of the presented creep equation was investigated with time-dependent laboratory experiments on cylindrical specimens and compared with the performances of four existing creep models.
\end{abstract}

\section{Introduction}

The restraint of creep as well as shrinkage strains causes the mechanical strain and becomes a source of persistent change in the creep-causing mechanism. This type of creep development forms a circulating loop with a mechanical significance that is the same as the creep strain developed under a timevarying stress history. Mathematical modeling of the creep mechanism is formulated in terms of the age and concrete properties at loading. Aside from the effect of time-varying stress history on the creep model, another aspect concerning the creep model is the formulation format where the creep model is combined with the age-dependent constitutive model that relates the change of stress with the mechanical strain developed due to the restraint of creep and shrinkage. When the creep model is combined with the constitutive model, a consistent formulation framework is required between the two models, such as the total time-based or incremental time-based formulation frameworks. The consistency requirement in the formulation framework is further extended to the global equilibrium equations to compute the nodal displacements whose formulation strongly depends on the type of constitutive descriptions. A number of studies regarding the formulation of global equilibrium equations have been presented in the total time-based format of the finite element analysis scheme and applied to the timedependent behaviors of concrete structures [1-3]. In this paper, a creep model is formulated within the incremental framework of the formulation to be consistent with the incremental format of the constitutive model.

Most studies regarding creep models have been performed to model the creep phenomena under various conditions of mix proportions, curing environments, ages of loading, and geometrical shape and dimensions [4-11]. However, focusing on the circulating loop phenomenon occurring in the time-dependent analysis of concrete structures, the creep model concentrates on depicting the creep strain developed under the time history loadings applied at different ages. A simple and robust method to model creep strain under time-varying stress history is a step-by-step method based 


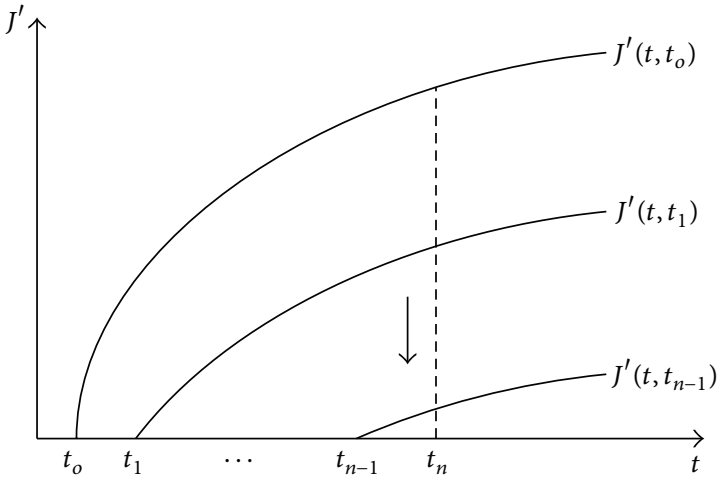

(a)

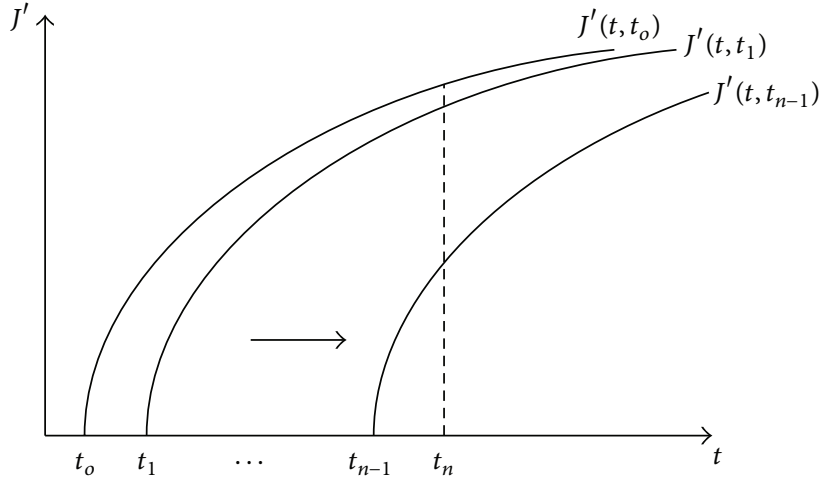

(b)

FIgURE 1: Parallel creep curves: (a) vertical parallel creep curve and (b) horizontal parallel creep curve.

on the principle of superposition. The formulation subdivides the entire stress history with stepwise variations of stress, which are called incremental stresses, applied at the end of a small time interval [11]. However, it is a difficult task to define the number of creep curves corresponding to the number of time intervals with stress increments. A great deal of effort has been made to model creep curves. The related studies are well introduced in the books of the ACI Committee 209 [5], Bažant and Wittmann [12], CEB [9], Ghali et al. [13], Gilbert [14], Gilbert and Ranzi [11], Jirasek and Bažant [15], and Rusch et al. [16]. Among the number of studies presented in the literature, four creep models draw attention to depict the circulating loop phenomenon: the rate of creep method (RCM) [17], step-by-step method [11], effective modulus method [18], and ageing coefficient method [19]. The performance of the models had been extensively studied by Gilbert and Ranzi [11] through a comparison of the mathematical formulations and numerical applications. Each model shows a different performance depending on the assumption made regarding the ageing effects of concrete loaded at different ages. Among these four models presented in the literature, special attention is given to RCM [17] because of its simple single-curve representation of creep behavior under a time-varying stress history. However, this method significantly underestimates the creep strain when it is applied to the creep problem subjected to persistent change in creep-causing stress. This paper presents a model to improve the disadvantage observed in RCM by introducing a horizontal parallel creep curve.

RCM is often referred to as the parallel creep curve method because the creep curves due to the loadings at different ages are assumed to be parallel. The term "parallel" in this method means that the tangents of the creep curves are identical along a vertical line. However, the method suffers from a significant underestimation of creep strain because of the parallel assumption when the sustained loads are applied at different ages. To remedy this inherent limitation, a horizontal parallel creep curve assumption is introduced and combined with the vertical parallel creep assumption of RCM. This type of formulation provides a creep strain bounded between upper and lower limits, where the lower limit is defined by RCM and the upper limit is defined by the horizontal parallel creep curve assumption. As a result, the presented creep formulation has the advantage of a single-curve representation for depicting creep strains under a time-varying stress history.

Two sets of laboratory experiments were sequentially conducted on cylindrical specimens to obtain the model parameters and to investigate the performance of the presented, two-way parallel creep curve formulation. Both sets of experiments included two cases of axial loads, including both constant and stepwise loads, where the stepwise loads were designed to depict the time-varying stress history. The performance of the presented creep model was compared with the effective modulus method, ageing coefficient method, stepby-step method, and RCM.

\section{Formulation of Creep}

The RCM, originally proposed by Glanville [17], assumes that the change in the rate of creep with time is independent of the age of loading. This means that the creep curves for concrete loaded at different times are assumed to be parallel. The meaning of "parallel" is illustrated in Figure 1(a), which shows creep curves corresponding to loads applied at different times $t_{o}, t_{1}, t_{2}, t_{3}, \ldots, t_{n-1}$. RCM underestimates creep strain because of the inherent limitation imposed by the parallel assumption, as observed from Figure 1(a). Therefore, a parallel creep curve along the horizontal direction is introduced, as shown in Figure 1(b), and combined with the vertical parallel creep curve of RCM. The relationship between the creep function $J^{\prime}\left(t, t_{o}\right)$, creep coefficient $\varphi\left(t, t_{o}\right)$, and creep compliance function $J\left(t, t_{o}\right)$ under a constant stress $\sigma\left(t_{o}\right)$ applied at time $t_{o}$ follows the convention of

$$
\begin{aligned}
\varepsilon(t) & =\frac{1+\varphi\left(t, t_{o}\right)}{E_{c}\left(t_{o}\right)} \sigma_{c}\left(t_{o}\right) \\
& =\left\{\frac{1}{E_{c}\left(t_{o}\right)}+J^{\prime}\left(t, t_{o}\right)\right\} \sigma_{c}\left(t_{o}\right)=J\left(t, t_{o}\right) \sigma_{c}\left(t_{o}\right) .
\end{aligned}
$$

Denoting the vertical parallel creep function as $J_{v}^{\prime}\left(t, t_{n-1}\right)$ and the horizontal parallel creep function as $J_{h}^{\prime}\left(t, t_{n-1}\right)$, 


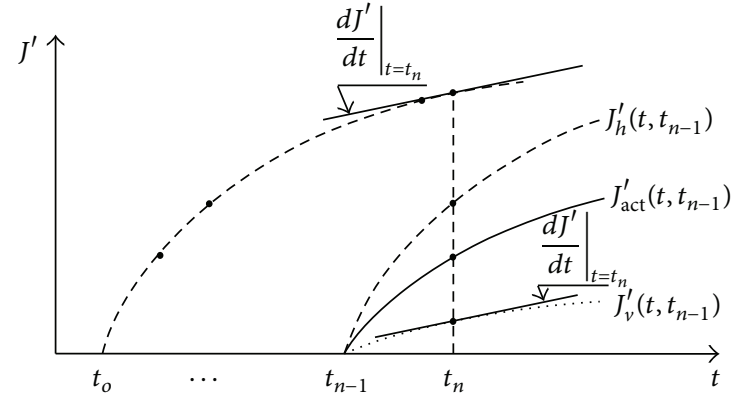

Figure 2: Concept of the two-way creep model.

the actual creep function $J_{\text {act }}^{\prime}\left(t, t_{n-1}\right)$ due to load applied at time $t_{n-1}$ ranges between $J_{v}^{\prime}\left(t, t_{n-1}\right)$ and $J_{h}^{\prime}\left(t, t_{n-1}\right)$. Figure 2 shows the relation among the three creep functions due to the load applied at time $t=t_{n-1}$. The relation among the three creep functions $J_{v}^{\prime}\left(t, t_{n-1}\right)<J_{\text {act }}^{\prime}\left(t, t_{n-1}\right)<J_{h}^{\prime}\left(t, t_{n-1}\right)$ was linearly interpolated in the subsequent model formulation by introducing the ageing factor $\alpha(t)$ as follows:

$$
\begin{aligned}
J_{\text {act }}^{\prime}\left(t, t_{n-1}\right)= & \left\{1-\alpha\left(t_{n-1}\right)\right\} J_{v}^{\prime}\left(t, t_{n-1}\right) \\
& +\alpha\left(t_{n-1}\right) J_{h}^{\prime}\left(t, t_{n-1}\right),
\end{aligned}
$$

where the ageing factor $\alpha\left(t_{n-1}\right)$ is used to adjust the decrease in creep over time and ranges between 0 and 1 . The remaining part of this paper is focused on formulating the two creep functions $J_{v}^{\prime}\left(t, t_{n-1}\right)$ and $J_{h}^{\prime}\left(t, t_{n-1}\right)$ in the form of the initial creep function $J^{\prime}\left(t, t_{o}\right)$, defining the creep strain due to the first load applied at time $t_{o}$, which leads to the single creep curve under a time-varying stress history.

2.1. One-Way Rate of Creep Formulation. Based on the RCM shown in Figure 1(a), the creep strain $\varepsilon_{\mathrm{cr}}^{i-1}\left(t_{n}\right)$ at time $t_{n}$ due to the loading at time $t_{i-1}$ is calculated with the vertical parallel creep function $J_{v}^{\prime}\left(t_{n}, t_{i-1}\right)$ as

$$
\varepsilon_{\mathrm{cr}}^{i-1}\left(t_{n}\right)=J_{v}^{\prime}\left(t_{n}, t_{i-1}\right) \Delta \sigma\left(t_{i-1}\right),
$$

where $\Delta \sigma\left(t_{i-1}\right)$ is the stress increment at time $t_{i-1}$. Denoting the creep function due to the first loading at the initial time $t_{o}$ as $J^{\prime}\left(t, t_{o}\right)$, the vertical parallel creep function $J_{v}^{\prime}\left(t_{n}, t_{i-1}\right)$ due to the loading at time $t_{i-1}$ is identical to $J^{\prime}\left(t_{n}, t_{o}\right)-J^{\prime}\left(t_{i-1}, t_{o}\right)$. Thereby, the creep strain $\varepsilon_{\mathrm{cr}}\left(t_{n}\right)$ at time $t_{n}$ due to the loadings at times $t_{o}, t_{1}, t_{2}, t_{3}, \ldots, t_{n-1}$ can be computed by summing the creep strains calculated from (3) as

$$
\varepsilon_{\mathrm{cr}}\left(t_{n}\right)=\sum_{i=1}^{n}\left\{J^{\prime}\left(t_{n}, t_{o}\right)-J^{\prime}\left(t_{i-1}, t_{o}\right)\right\} \Delta \sigma\left(t_{i-1}\right) .
$$

The increment of creep strain $\Delta \varepsilon_{\text {cr }}\left(t_{n}\right)$ during the time change from $t_{n-1}$ to $t_{n}$ is computed by expressing (4) in incremental form:

$$
\Delta \varepsilon_{\mathrm{cr}}\left(t_{n}\right)=\left.\Delta J^{\prime}\right|_{t=t_{n-1}} \sigma\left(t_{n-1}\right),
$$

where $\left.\Delta J^{\prime}\right|_{t=t_{n-1}}=J^{\prime}\left(t_{n}, t_{n-1}\right)=J^{\prime}\left(t_{n}, t_{o}\right)-J^{\prime}\left(t_{n-1}, t_{o}\right)$.
The integral form of (4) can be derived by expressing the incremental form of (5) as the rate form:

$$
\dot{\varepsilon}_{\mathrm{cr}}(t)=\dot{J}^{\prime}(t) \sigma(t) ; \quad \dot{J}^{\prime}(t)=\frac{d J^{\prime}(t)}{d t} .
$$

Integrating (6) from time $t_{o}$ to time $t$ leads to the integral form of the creep strain $\varepsilon_{\mathrm{cr}}(t)$ :

$$
\varepsilon_{\mathrm{cr}}(t)=\int_{t_{o}}^{t} \sigma(t) d J^{\prime}(t) .
$$

In this paper, the creep equation of (5) is termed the one-way RCM because the tangents of the creep curves are identical along a vertical line.

2.2. Two-Way Rate of Creep Formulation. A creep curve is introduced under the self-similarity assumption of Figure 1(b), where the tangents of the creep curves are identical along the horizontal direction. According to this assumption, the creep strain $\varepsilon_{\mathrm{cr}}^{i-1}\left(t_{n}\right)$ at time $t_{n}$ due to the loading at time $t_{i-1}$ is calculated with the horizontal parallel creep function $J_{h}^{\prime}\left(t_{n}, t_{i-1}\right)$ as

$$
\varepsilon_{\mathrm{cr}}^{i-1}\left(t_{n}\right)=J_{h}^{\prime}\left(t_{n}, t_{i-1}\right) \Delta \sigma\left(t_{i-1}\right) .
$$

Representing the horizontal parallel creep function $J_{h}^{\prime}\left(t_{n}, t_{i-1}\right)$ in the form of $J^{\prime}\left(t, t_{o}\right)$, the creep strain $\varepsilon_{\mathrm{cr}}\left(t_{n}\right)$ at time $t_{n}$ due to the loadings at times $t_{o}, t_{1}, t_{2}, t_{3}, \ldots, t_{n-1}$ can be computed by summing the creep strains calculated from (8) as

$$
\varepsilon_{\mathrm{cr}}\left(t_{n}\right)=\sum_{i=1}^{n} J^{\prime}\left(t_{n}-t_{i-1}+t_{o}, t_{o}\right) \Delta \sigma\left(t_{i-1}\right) .
$$

The relation of $J_{h}^{\prime}\left(t_{n}, t_{i-1}\right)=J^{\prime}\left(t_{n}-t_{i-1}+t_{o}, t_{o}\right)$ in (8) and (9) is obtained from the geometry of Figure 1(b), where the creep curve due to the loading at time $t_{i-1}$ is horizontally projected to the initial creep curve $J^{\prime}\left(t, t_{o}\right)$.

The incremental expression $\Delta \varepsilon_{c r}\left(t_{n}\right)$ of (9) can be obtained similarly to the RCM:

$$
\Delta \varepsilon_{\mathrm{cr}}\left(t_{n}\right)=\sum_{i=1}^{n} \Delta J_{i-1}^{\prime}\left(t_{n}\right) \Delta \sigma\left(t_{i-1}\right),
$$

where $\Delta J_{i-1}^{\prime}\left(t_{n}\right)=J^{\prime}\left(t_{n}-t_{i-1}+t_{o}, t_{o}\right)-J^{\prime}\left(t_{n-1}-t_{i-1}+\right.$ $\left.t_{o}, t_{o}\right)$ represents the increment of the creep function due to the loading at time $t_{i-1}$, from time $t_{n-1}$ to time $t_{n}$. The full expression of (10) is derived by expressing $\Delta \varepsilon_{\mathrm{cr}}\left(t_{n}\right)$ in (10) as the rate form as follows:

$$
\dot{\varepsilon}_{\mathrm{cr}}^{i-1}(t)=\dot{\sigma}\left(t_{i-1}\right) \dot{J}_{i-1}^{\prime}(t),
$$

where $\dot{\varepsilon}_{\mathrm{cr}}^{i-1}(t)$ denotes the rate of the creep strain at time $t$ due to the load applied at time $t_{i-1}$. Integrating the rate of creep strain of (11) from time $t_{o}$ to time $t$ as well as summing all the creep curves corresponding to the loadings at times $t_{o}, t_{1}, t_{2}, t_{3}, \ldots, t_{n-1}$ leads to the integral form:

$$
\varepsilon_{\mathrm{cr}}(t)=\sum_{i=1}^{n} \Delta \sigma\left(t_{i-1}\right) \int_{t_{o}}^{t-t_{i-1}+t_{o}} d J^{\prime}(t) .
$$


Since the actual creep curve shown in Figure 2 is bounded between the two limits of (4) and (9) (or (7) and (12), if expressed in integral form), the two limit cases of the creep strain are combined by the ageing factor $\alpha(t)$ defined in (2). The resulting incremental expression of creep strain can be obtained by combining (5) and (10) as follows:

$$
\begin{aligned}
\Delta \varepsilon_{\mathrm{cr}}\left(t_{n}\right)= & \left.\left(1-\alpha_{n}\right) \Delta J^{\prime}\right|_{t=t_{n-1}} \sigma\left(t_{n-1}\right) \\
& +\alpha_{n} \sum_{i=1}^{n} \Delta J_{i-1}^{\prime}\left(t_{n}\right) \Delta \sigma\left(t_{i-1}\right),
\end{aligned}
$$

where $\alpha_{n}=\alpha\left(t_{n}\right)$. The creep equation of (13) combines the two equality assumptions for the tangents of the creep curves along the vertical and horizontal directions. The equality assumption along the vertical direction corresponds to the case of $\alpha=0$ and provides the lower limit of the creep strain, whereas that along the horizontal direction corresponds to the case of $\alpha=1$ and provides the upper limit. The presented creep expression of (13) models the particular creep behavior under multiple time-varying loadings by combining the two ultimate creep formulations. The value of the ageing factor $\alpha(t)$ in (13) can be determined from a set of experiments, including creep tests under constant and stepwise loads. It is noted that the two-way rate of creep formulation of (13) only requires a single creep curve that depicts the creep strain under a constant load applied at time $t_{o}$ to calculate the creep strain under a time-varying stress history.

\section{Existing Creep Models}

3.1. Effective Modulus Method. The effective modulus method (EMM), presented by Faber [18], is the oldest and simplest method to calculate the creep strain of concrete subjected to a time-varying stress history. This method assumes that the magnitude of the creep function due to the loading at time $t_{i-1}$ is the same as the magnitude of the initial creep function $J^{\prime}\left(t_{n}, t_{o}\right)$ due to the loading at time $t_{o}$. Therefore, the creep strain $\varepsilon_{\mathrm{cr}}\left(t_{n}\right)$ and the corresponding total strain $\varepsilon\left(t_{n}\right)$ due to the total stress $\sigma_{c}\left(t_{n}\right)$ at time $t_{n}$ can be calculated as

$$
\begin{aligned}
\varepsilon_{\mathrm{cr}}\left(t_{n}\right) & =\frac{\varphi\left(t_{n}, t_{o}\right)}{E_{c}\left(t_{o}\right)} \sigma_{c}\left(t_{n}\right)=J\left(t_{n}, t_{o}\right) \sigma_{c}\left(t_{n}\right), \\
\varepsilon & \left(t_{n}\right)=\left\{\frac{1+\varphi\left(t_{n}, t_{o}\right)}{E_{c}\left(t_{o}\right)}\right\} \sigma_{c}\left(t_{n}\right)+\varepsilon_{\mathrm{sh}}\left(t_{n}\right) \\
& =\frac{1}{E_{\mathrm{ce}}\left(t_{n}, t_{o}\right)} \sigma_{c}\left(t_{n}\right)+\varepsilon_{\mathrm{sh}}\left(t_{n}\right),
\end{aligned}
$$

where $E_{\text {ce }}\left(t_{o}\right)$ is the effective modulus. The total stress $\sigma_{c}\left(t_{n}\right)=$ $\sum_{i=1}^{n} \Delta \sigma\left(t_{i-1}\right)$ is the sum of the loads applied at different times $t_{o}, t_{1}, t_{2}, t_{3}, \ldots, t_{n-1}$. This method computes the largest value for the creep strain among the five creep models considered in this paper in the case of a time-varying stress history.

3.2. Ageing Coefficient Method. An ageing coefficient $\chi\left(t, t_{o}\right)$ was introduced to the effective modulus method of Faber by Bažant [19] to account for the age-dependency of creep at loading of which the earlier the concrete is loaded, the greater the creep strain is (referred to as the age-adjusted effective modulus method (AEMM)). The creep strain $\varepsilon_{\mathrm{cr}}\left(t_{n}\right)$ and total strain $\varepsilon\left(t_{n}\right)$ at time $t_{n}$ can be presented with the age-adjusted effective modulus $\bar{E}_{\mathrm{ce}}\left(t_{o}\right)$ as follows:

$$
\begin{aligned}
\varepsilon_{\mathrm{cr}}\left(t_{n}\right)= & \frac{\sigma_{c}\left(t_{o}\right)}{E_{c}\left(t_{o}\right)} \varphi\left(t_{n}, t_{o}\right) \\
& +\frac{\Delta \sigma_{c}\left(t_{n}\right)}{E_{c}\left(t_{o}\right)} \chi\left(t_{n}, t_{o}\right) \varphi\left(t_{n}, t_{o}\right), \\
\varepsilon\left(t_{n}\right)= & \left\{\frac{1+\varphi\left(t_{n}, t_{o}\right)}{E_{c}\left(t_{o}\right)}\right\} \sigma_{c}\left(t_{o}\right) \\
& +\left\{\frac{1+\chi\left(t_{n}, t_{o}\right) \varphi\left(t_{n}, t_{o}\right)}{E_{c}\left(t_{o}\right)}\right\} \Delta \sigma_{c}\left(t_{n}\right)+\varepsilon_{\mathrm{sh}} \\
= & \frac{\sigma_{c}\left(t_{o}\right)}{E_{\mathrm{ce}}\left(t_{n}, t_{o}\right)}+\frac{\Delta \sigma_{c}\left(t_{n}\right)}{\bar{E}_{\mathrm{ce}}\left(t_{n}, t_{o}\right)}+\varepsilon_{\mathrm{sh}},
\end{aligned}
$$

where $\bar{E}_{\mathrm{ce}}\left(t, t_{o}\right)$ is the age-adjusted effective modulus and $\Delta \sigma\left(t_{n}\right)$ is the stress variation during the time change from $t_{o}$ to $t_{n}$. In (16), the creep model of Faber is recovered when $\chi\left(t, t_{o}\right)=1$. Since the ageing coefficient $\chi\left(t, t_{o}\right)$ is dependent on the stress level $\Delta \sigma\left(t_{n}\right)$, its value is obtained from the creep test under the time-varying stress history. In the special case of pure relaxation where only an initial strain is applied, the value of $\chi\left(t, t_{o}\right)$ is computed from [11]. The most typical value of $\chi\left(t, t_{o}\right)=0.8$ was suggested from the general range of 0.5 to $1[15]$.

3.3. Step-by-Step Method. The step-by-step method (SSM) superimposes the creep strains due to the loadings at each time increment. In SSM, the continuously varying stress is divided by the specified time intervals, and the creep strain due to a stress increment at a time interval is calculated by the known creep function. Assuming the creep function $J_{i-1}^{\prime}\left(t_{n}, t_{i-1}\right)$ due to the stress increment $\Delta \sigma\left(t_{i-1}\right)$ at time interval $t_{i-1}$, the creep strain $\varepsilon_{\mathrm{cr}}^{i-1}\left(t_{n}\right)$ at time $t_{n}$ is calculated from

$$
\varepsilon_{\mathrm{cr}}^{i-1}\left(t_{n}\right)=J_{i-1}^{\prime}\left(t_{n}, t_{i-1}\right) \Delta \sigma\left(t_{i-1}\right) .
$$

Equation (18) is similar to (3) and (8). The difference between these equations, however, is found in the definition of the creep function, where, in (3) and (8), the initial creep curve due to the first loading at time $t_{o}$ defines the subsequent creep curves due to the loads at different times, while (18) requires the same number of creep functions as there are loads. Upon determination of the creep functions, the total creep strain $\varepsilon_{\mathrm{cr}}\left(t_{n}\right)$ at time $t_{n}$ can be obtained by superimposing the creep contributions from each time interval as

$$
\varepsilon_{\mathrm{cr}}\left(t_{n}\right)=\sum_{i=1}^{n} J_{i-1}^{\prime}\left(t_{n}, t_{i-1}\right) \Delta \sigma\left(t_{i-1}\right) .
$$

\section{Experiments and Numerical Predictions}

Two sets of time-dependent laboratory experiments of types $\mathrm{A}$ and $\mathrm{B}$ were sequentially conducted on cylindrical concrete 
TABLE 1: Mixture proportions for the two test types of concrete.

\begin{tabular}{|c|c|c|c|c|c|c|c|}
\hline \multirow{2}{*}{ Test type } & \multirow{2}{*}{ Max. size of aggr. (mm) } & \multirow{2}{*}{$\mathrm{W} / \mathrm{C}$ ratio $(\%)$} & \multirow{2}{*}{ Slump $(\mathrm{mm})$} & \multicolumn{4}{|c|}{ Unit weight, $\left(\mathrm{N} / \mathrm{m}^{3}\right)$} \\
\hline & & & & Water & Cement & Fine aggr. & Coarse aggr. \\
\hline Type A & 20 & 54 & 110 & 1,880 & 3,480 & 7,360 & 10,200 \\
\hline Type B & 20 & 57 & 200 & 2,120 & 3,720 & 9,450 & 7,610 \\
\hline
\end{tabular}

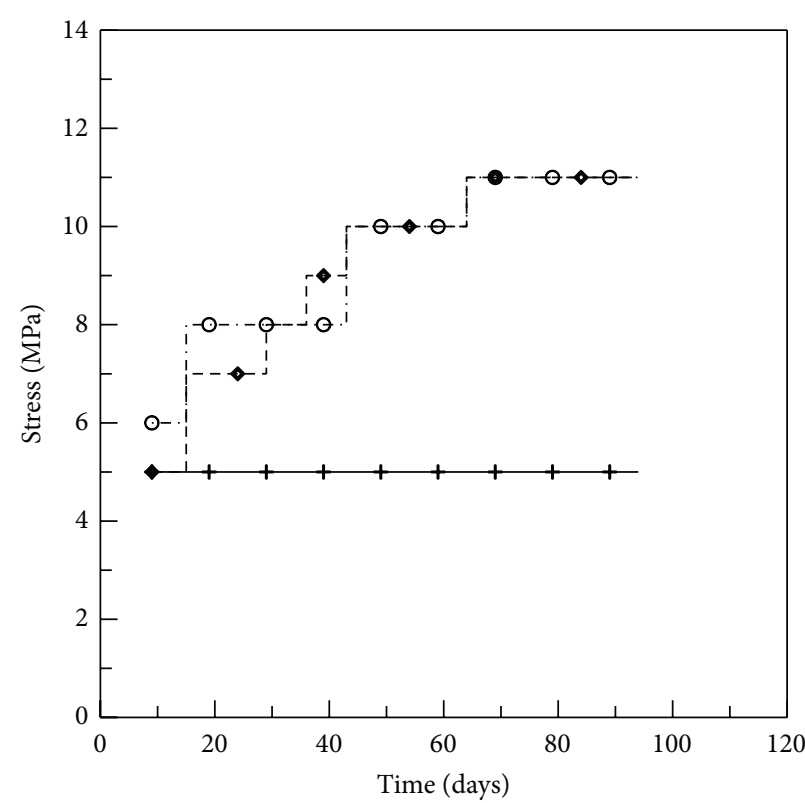

Type A

+ Constant load

- - Stepwise load case 1

- - - Stepwise load case 2

(a)

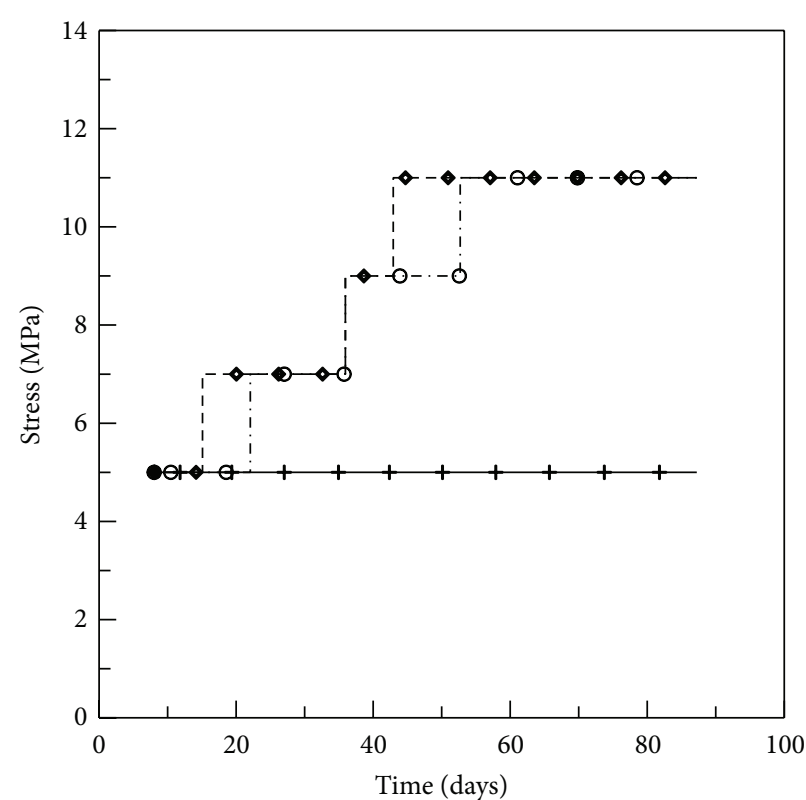

Type B

+ Constant load

- - Stepwise load case 1

○- Stepwise load case 2

(b)

Figure 3: Stepwise loads applied to (a) type A test and (b) type B test.

specimens to determine the value of the ageing factor $\alpha(t)$ defined in (2) and (13). Two load cases, including constant and stepwise loads, were taken into account to find the value of the ageing factor in type A test. The same load cases were employed to type B test to validate the value of the ageing factor obtained.

4.1. Cylindrical Concrete Specimens. All cylindrical concrete specimens were cast with $150 \mathrm{~mm}$ diameter and $300 \mathrm{~mm}$ height. For each type of test, thirty-five cylindrical concrete specimens were cast, of which twelve specimens were used for the creep tests in uniaxial compression, three specimens were used to measure the shrinkage, and twenty specimens were used to measure the development of the elastic modulus. Table 1 lists the concrete mixture proportions for the cylindrical specimens for the two test types where different slump values were taken to provide more experimental evidence for the performance of the presented creep formulation. All the specimens were covered with nonwoven fabric so that they were not exposed to the air and were fully moisturized by sprinkling water until the formworks were removed. The specimens were removed from the molds 24 hours after casting and then cured in water. At the age of 10 days (7 days for type B test), the initial value of the elastic modulus was measured from a direct compression test. Test data, including creep, shrinkage, and elastic modulus, were obtained from strain gages attached at the midheight of the specimen at equal angles of $90^{\circ}$. Six creep-testing apparatuses were used for the creep tests where two specimens were set in series in each apparatus. Two of the testing apparatuses were used to measure the creep strain under a constant load. The other four were used to measure creep strains under the two cases of stepwise loads. Figures 3(a) and 3(b) show the load histories of the two stepwise load cases applied to type A and type B tests, respectively.

Hydraulic pressure was applied by a hydraulic jack. The pressure level was monitored by a pressure meter attached to the jack and a load cell mounted at the top of the specimen throughout the testing period (see Figure 4). Since the leak of hydraulic pressure causes undesirable specimen deformation, the locking bolts in Figure 4 were locked immediately after the hydraulic pressure was applied. However, the locking of the bolts did not interfere with the release of the spring that was induced, owing to the progressive deformation of 
TABLE 2: Three empirical equations for the two types of tests.

\begin{tabular}{lcccccccccc}
\hline Test type & \multicolumn{1}{c}{ Parameters } \\
& $a_{1}$ & $b_{1}$ & $a_{2}$ & $b_{2}$ & $a_{3}$ & $b_{3}$ & $t_{o}($ days $)$ & $E_{c}\left(t=t_{o}\right)(\mathrm{MPa})$ & $E_{c}(t=28)(\mathrm{MPa})$ & 32,800 \\
$\mathrm{~A}$ & 9.5 & 1.7 & 51 & 1.45 & 4 & 0.85 & 10 & 29,400 & 25,300 \\
$\mathrm{~B}$ & 11.4 & 5.1 & 48.4 & 0.73 & 2.6 & 0.9 & 7 & 22,700 & $f_{c}^{\prime}(\mathrm{MPa})$ \\
\hline & \multicolumn{4}{c}{$J^{\prime}\left(t, t_{o}\right)=\frac{\left(t-t_{o}\right)^{0.6}}{a_{1}+\left(t-t_{o}\right)^{0.6}} \frac{b_{1}}{E_{c}\left(t=t_{o}\right)}, \varepsilon_{\mathrm{sh}}\left(t, t_{o}\right)=\frac{\left(t-t_{o}\right)}{a_{2}+b_{2}\left(t-t_{o}\right)} \varepsilon_{\text {shu }}, E_{c}(t)=\sqrt{\frac{t}{a_{3}+b_{3} t} E_{c}(t=28 \text { days })}$} \\
\hline
\end{tabular}

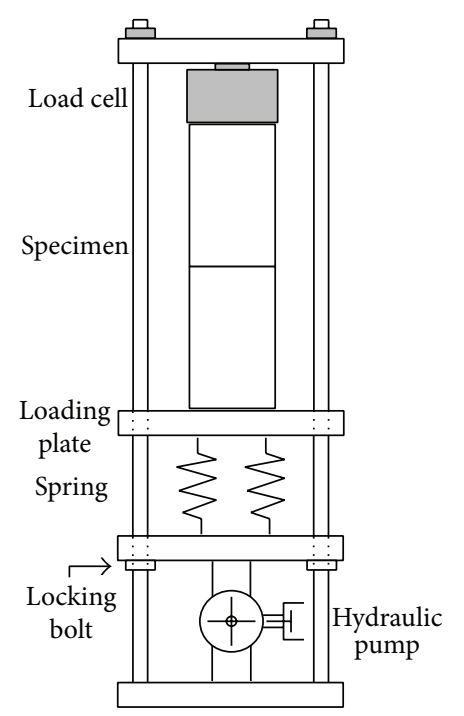

FIGURE 4: Schematic drawing of creep test setup.

the specimen. The loss of axial pressure due to the release of the spring was supplemented every two days to maintain the pressure level, as designated in Figures 3(a) and 3(b).

4.2. Basic Age-Dependent Properties. All experiments were conducted in a controlled room with a constant temperature of $22 \pm 11^{\circ} \mathrm{C}$ and relative humidity of $60 \pm 2 \% \mathrm{RH}$ for 120 days. Gage readings from the specimens were automatically stored every minute in a data acquisition system with 81 data channels. All stored data were extracted from the acquisition system every 7 days to avoid an accidental loss of data. For the creep test under constant load, an initial pressure of $5 \mathrm{MPa}$ was applied at the age of 10 days for type A test (7 days for type $\mathrm{B}$ test). For the creep test under stepwise loads, initial pressure values of 5 and $6 \mathrm{MPa}$ were applied, respectively, for the two stepwise load cases of type A test, and the same initial pressure of $5 \mathrm{MPa}$ was applied for the two load cases of type B test. The final axial pressure was $11 \mathrm{MPa}$ at the end of the stepwise loadings for both type A and type B tests (Figures 3(a) and 3(b)).

When concrete is loaded with a time-varying stress history, the present single-curve formulation requires a creep curve that describes the creep strain under a constant load. The creep curve was calibrated from the constant load case for both type A and type B tests. The resulting three equations of creep strain to define $J^{\prime}\left(t, t_{o}\right)$, shrinkage strain, and development of elastic modulus are listed in Table 2 . The values of the elastic modulus were measured at the ages of 7 (10 in type A test), 14,28 , and 56 days. The parameter $\varepsilon_{\text {shu }}=7.8 \times 10^{-4}$ in Table 2 defines the shrinkage strain at $t=\infty$ according to $[5,9]$, and $f_{c}^{\prime}$ is the uniaxial compressive strength at the age of 28 days. Figures 5(a) and 5(b) show the total, creep, and shrinkage strains, as well as development of the elastic modulus for type A test, respectively, where the creep strain was obtained by subtracting the immediate elastic strain and shrinkage strain from the total strain measurements.

4.3. Determination of the Ageing Factor Value. The value of the ageing factor $\alpha(t)$ defining the creep formulation in (2) and (13) was determined from the creep tests under the stepwise loads depicted in Figure 3(a). Figures 6(a) and 6(b) compare the measured and predicted total strains where the measured total strain for each load case was obtained by averaging the total strains measured from four specimens. The numerical predictions were conducted by increasing the value of $\alpha$ from 0 to 1 in 0.25 increments, where $\alpha=\alpha(t)$ was assumed to be independent of time. The creep strains were extracted by subtracting the immediate elastic strain and shrinkage strain from the total strains and compared in Figures 7(a) and 7(b) for the two load cases 1 and 2, respectively. It is observed from Figures 6 and 7 that the creep strain is significantly underestimated in the vertical parallel creep curve method corresponding to $\alpha=0$, whereas it is overestimated in the horizontal parallel creep curve assumption corresponding to $\alpha=1$. The value of the ageing factor $\alpha=0.75$, obtained from the comparisons, indicates that, in the current creep formulation, the creep strain is predominantly predicted by the horizontal parallel creep curve assumption, rather than the vertical creep curve assumption for concrete loaded at a relatively early age.

Strain measurements of the two stepwise load cases for type B test in Figure 3(b) were predicted by the presented creep model to verify whether the value of the ageing factor $\alpha=0.75$, obtained from type A test, is acceptable. The value of the ageing factor was increased in the prediction from $\alpha=0$ to $\alpha=1$ with 0.25 increments. Three basic equations used in the analysis are listed in Table 2 where the creep function was obtained from the creep test under a constant pressure of $5 \mathrm{MPa}$. Total strains measured for the two stepwise load cases 1 and 2 are compared to the predicted strains in Figures 8(a) and 8(b), respectively. The creep strains are compared in Figures 9(a) and 9(b) for the two load cases 1 and 2, respectively. It is noted from Figures 8 and 9 that the measured strains match well with the predicted strains for the two stepwise load cases when $\alpha=0.75$, and the development of creep is similar to type A test. 


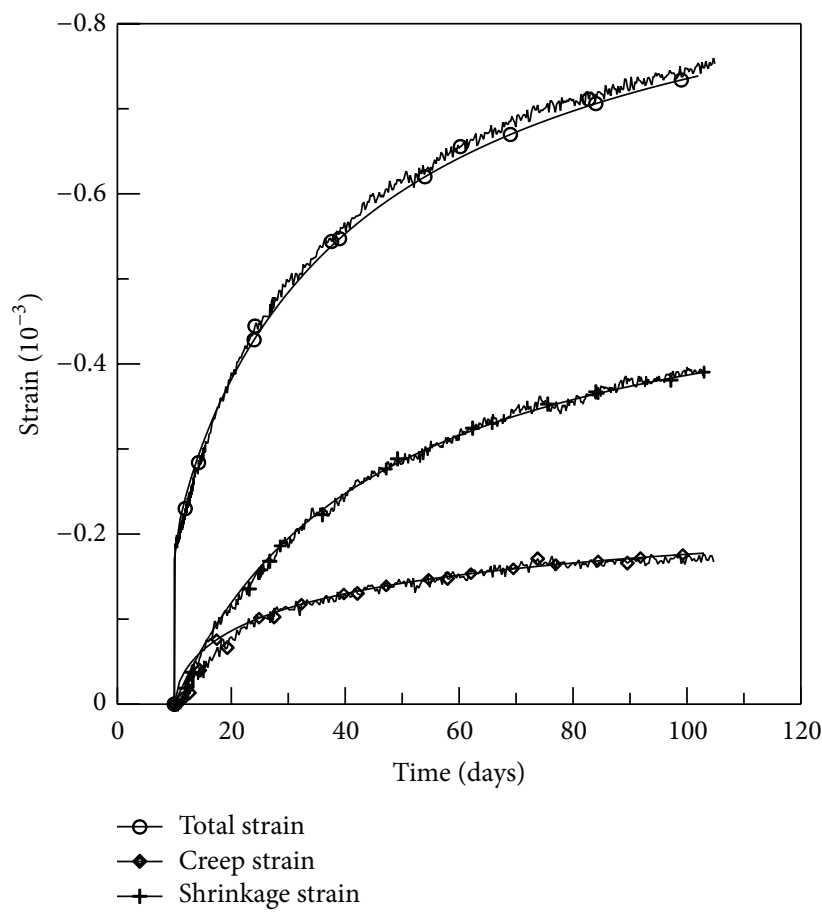

(a)

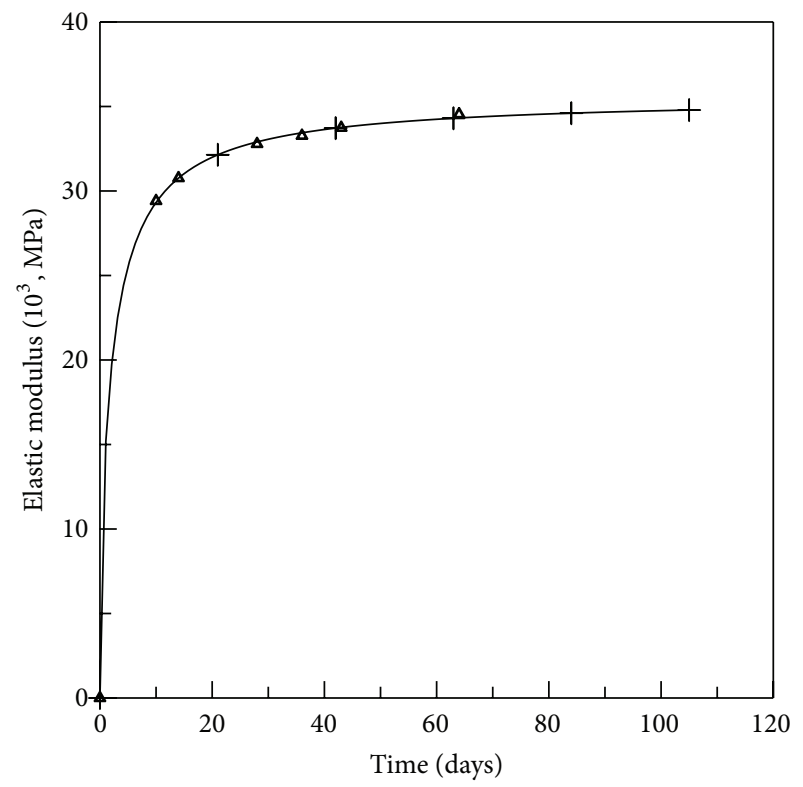

FIGURE 5: Basic age-dependent properties of type A test: (a) total, creep, and shrinkage strains, (b) development of elastic modulus.

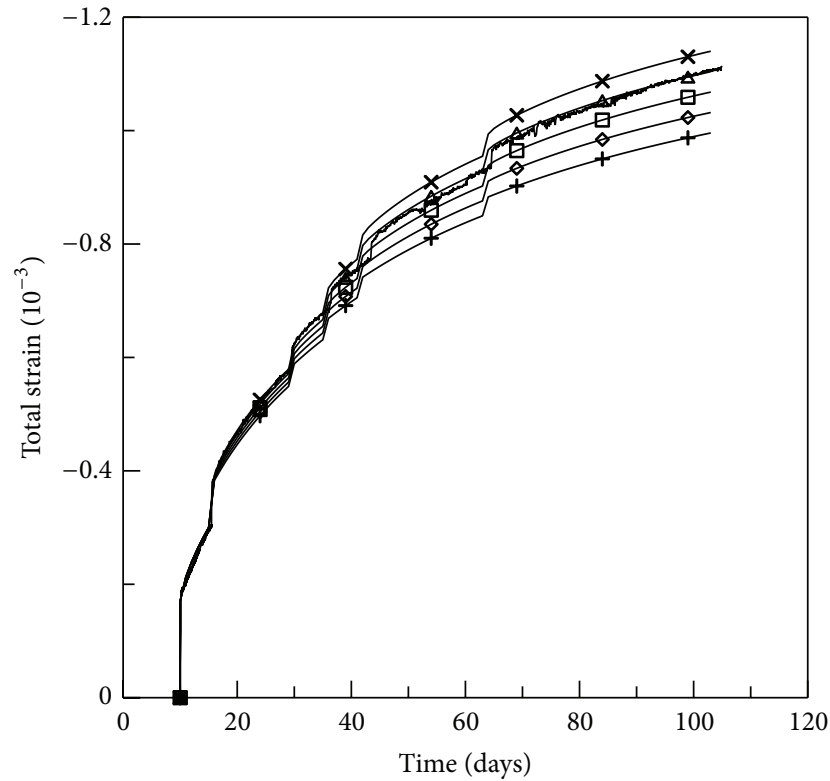

Type A

Stepwise (load case 1)

$\rightarrow$ Predicted $\alpha=0.0$

$\multimap$ Predicted $\alpha=0.25$

$\square$ Predicted $\alpha=0.5$

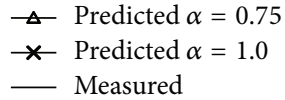

— Measured

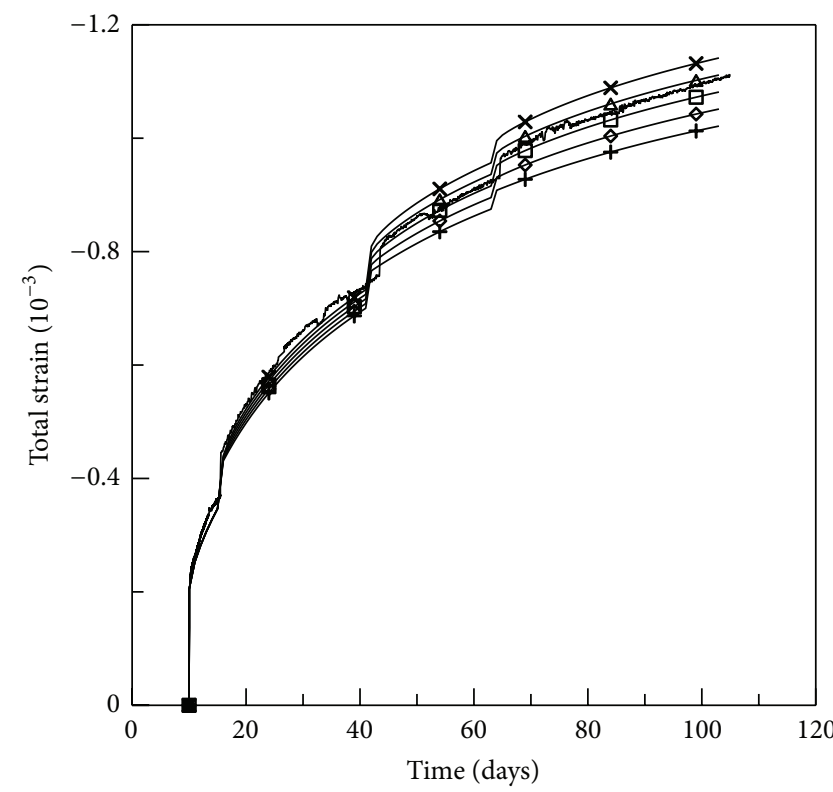

Type A

Stepwise (load case 2)

$\rightarrow$ Predicted $\alpha=0.0$

$\multimap$ Predicted $\alpha=0.25$

七 Predicted $\alpha=0.5$

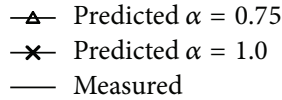

(b)

FIgURE 6: Predicted and measured total strains for the two stepwise load cases of type A test: (a) load case 1 and (b) load case 2. 


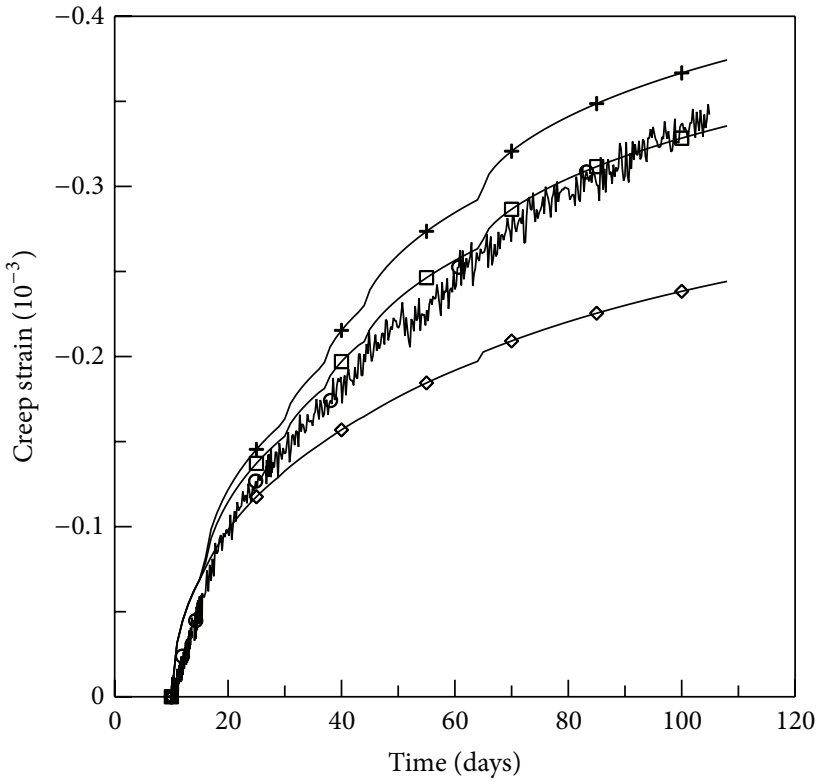

Type A

Stepwise (load case 1)

- - Measured

+ Predicted $\alpha=1.0$

(a)

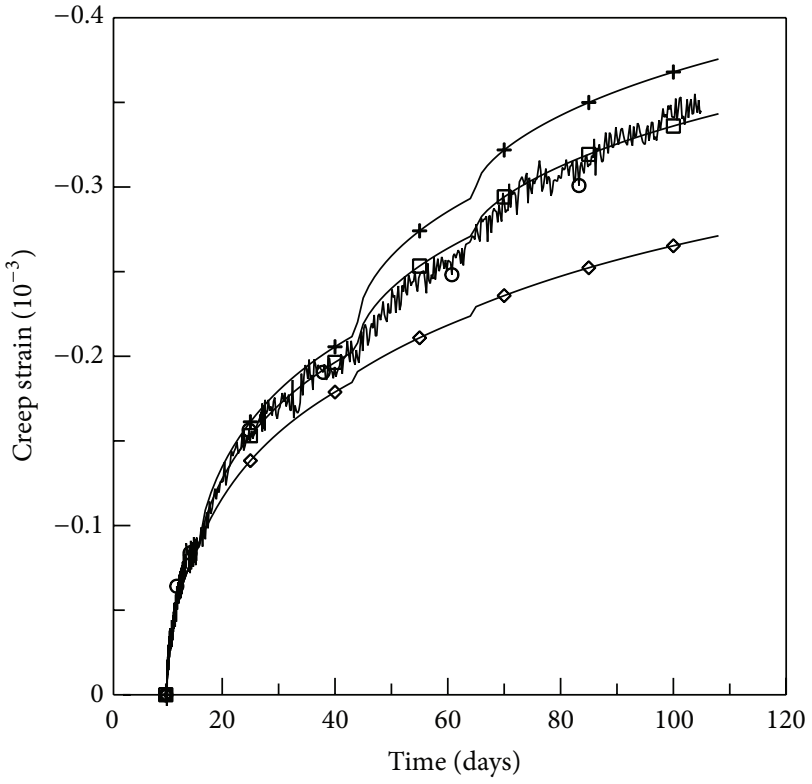

Type A

Stepwise (load case 2)

+ Measured
+ Predicted $\alpha=1.0$

(b)

FIGURE 7: Predicted and measured creep strains for the two stepwise load cases of type A test: (a) load case 1 and (b) load case 2.

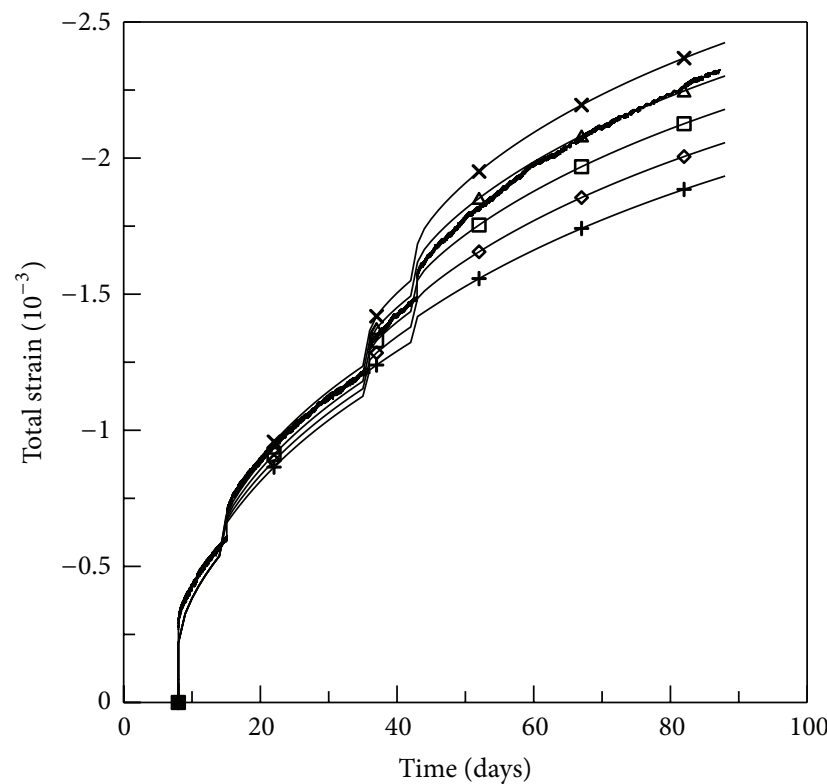

Type B

Stepwise (load case 1)

$\rightarrow$ Predicted $\alpha=0.0$

$\multimap$ Predicted $\alpha=0.25$

๑- Predicted $\alpha=0.5$

(a)

$\times$ Predicted $\alpha=1.0$

Measured

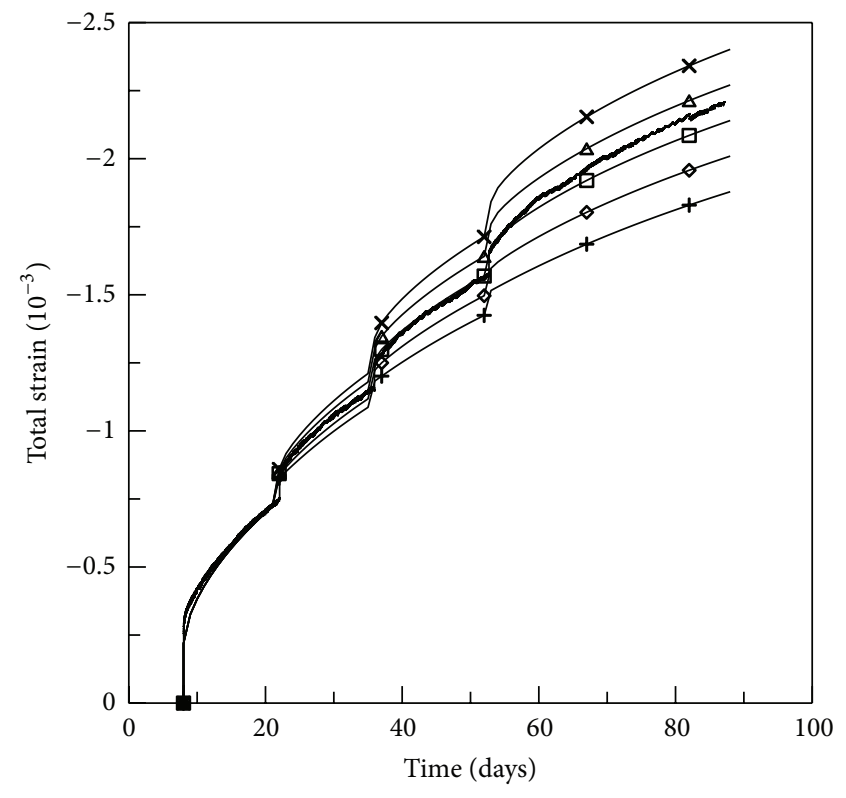

Type B

Stepwise (load case 2)

+ Predicted $\alpha=0.0$

$\multimap$ Predicted $\alpha=0.25$

$\square$ Predicted $\alpha=0.5$

(b)

Figure 8: Predicted and measured total strains for the two stepwise load cases of type B test: (a) load case 1 and (b) load case 2. 


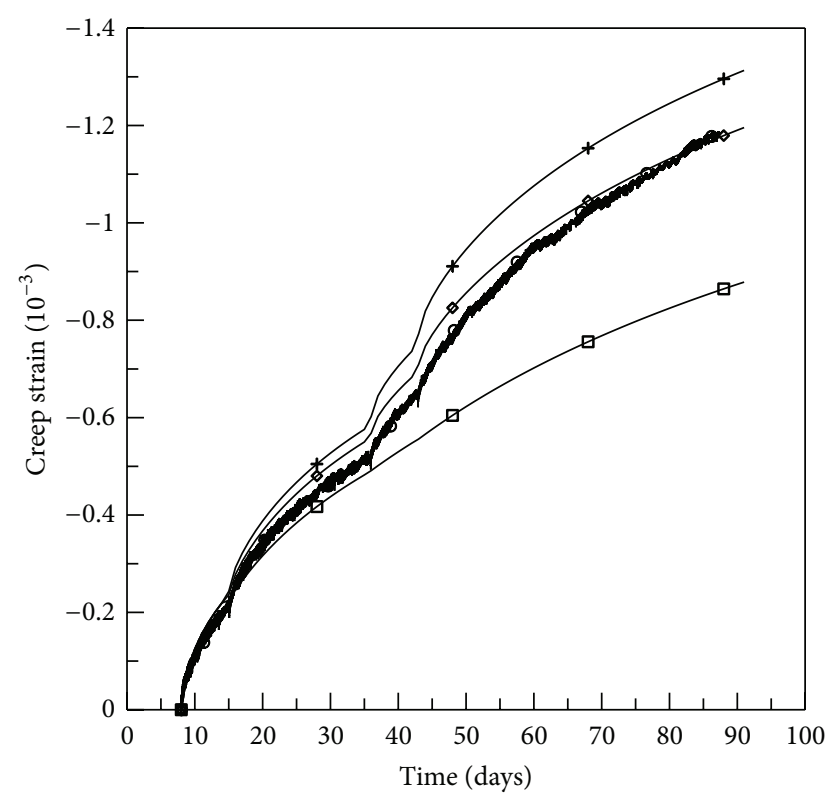

Type B

Stepwise (load case 1)

$$
\begin{aligned}
& + \text { Measured } \\
& +- \text { Predicted } \alpha=1.0
\end{aligned}
$$$$
\begin{aligned}
& \rightarrow \text { Predicted } \alpha=0.75 \\
& \rightarrow \text { Predicted } \alpha=0
\end{aligned}
$$

(a)

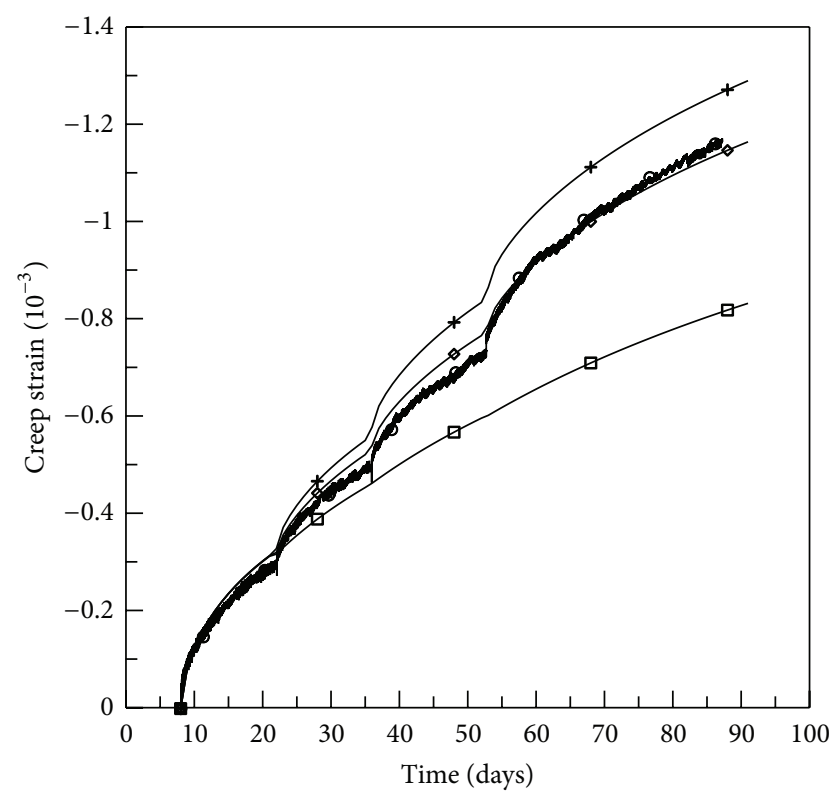

Type B

Stepwise (load case 2)

- - Measured

+ Predicted $\alpha=1.0$

(b)

FIGURE 9: Predicted and measured creep strains for the two stepwise load cases of type B test: (a) load case 1 and (b) load case 2.

4.4. Prediction by Existing Creep Models. Strain measurements for the two stepwise load cases of type A and type B tests were predicted and compared using five creep models, including EMM, AEMM, RCM, SSM, and the method presented in this study. A constant value of the ageing coefficient $\chi\left(t, t_{o}\right)=0.8$ was used in the AEMM case. The values of the elastic moduli $E_{c}\left(t_{o}=10\right.$ days $)$ and $E_{c}\left(t_{o}=7\right.$ days $)$ for type $A$ and type $B$ tests in Table 2, respectively, defined the elastic modulus in (15) and (17).

In the SSM case, the continuous creep function $J^{\prime}\left(t, t_{o}\right)$ for the two stepwise load cases in Figure 3 were obtained based on ACI 209R-92 [2]. According to ACI 209R-92, the creep function $J^{\prime}\left(t, t_{i-1}\right)$ due to the loading at time $t_{o}$ is computed from

$$
J^{\prime}\left(t, t_{i-1}\right)=\frac{\left(t-t_{i-1}\right)^{\psi}}{a+\left(t-t_{i-1}\right)^{\psi}} \frac{\phi_{u}\left(t_{i-1}\right)}{E_{c}\left(t_{i-1}\right)},
$$

where $\phi_{u}\left(t_{i-1}\right)$ is the ultimate creep coefficient defined with six correction factors in the case of nonstandard conditions. The coefficient $\phi_{u}\left(t_{i-1}\right)$ accounts for the correction factor for the time at loading under moist curing conditions as follows:

$$
\phi_{u}\left(t_{i-1}\right)=b \gamma_{c, t_{i-1}},
$$

where $\gamma_{c, t_{i-1}}=1.25 t_{i-1}^{-0.118}$ is the correction factor due to the time at loading. Substituting (21) into (20), the creep function $J^{\prime}\left(t, t_{i-1}\right)$ at loading time $t_{i-1}$ is obtained as follows:

$$
J^{\prime}\left(t, t_{i-1}\right)=\frac{\left(t-t_{i-1}\right)^{\psi}}{a+\left(t-t_{i-1}\right)^{\psi}} \frac{1.25 b t_{i-1}^{-0.118}}{E\left(t_{i-1}\right)} .
$$

The parameter values $a, \psi$, and $b$ in (22) were determined through regression analyses for the creep tests of types $\mathrm{A}$ and $\mathrm{B}$ at loading times $t_{i-1}=10$ days and $t_{i-1}=7$ days, respectively (Table 2 ). The final forms of the creep functions, according to ACI 209R-92, were obtained as follows:

$$
\begin{aligned}
& J^{\prime}\left(t, t_{i-1}\right)=\frac{2.23\left\{t_{i-1}^{-0.118}\left(t-t_{i-1}\right)^{0.6}\right\}}{E\left(t_{i-1}\right)\left\{9.5+\left(t-t_{i-1}\right)^{0.6}\right\}} \quad(\text { type A }), \\
& J^{\prime}\left(t, t_{i-1}\right)=\frac{6.42\left\{t_{i-1}^{-0.118}\left(t-t_{i-1}\right)^{0.6}\right\}}{E\left(t_{i-1}\right)\left\{11.4+\left(t-t_{i-1}\right)^{0.6}\right\}}
\end{aligned}
$$

(type B).

The types of variables and the model format were compared among the five creep models to identify the model performance depending on those modeling factors. Three modeling factors were verified in the comparisons: whether the creep function accounts for the time-varying stress history, whether the development of the elastic modulus is taken into account in the model formulation, and whether the formulation format is based on incremental time or total time. Regarding the time-varying stress history, three models, AEMM, SSM, and the presented model, account for the timevarying stress history in their creep functions. Regarding the development of elastic modulus, two models, SSM and the presented model, take into account the change of elastic modulus at the age of loadings while the other three models, AEMM, EMM, and RCM, use the elastic modulus evaluated 

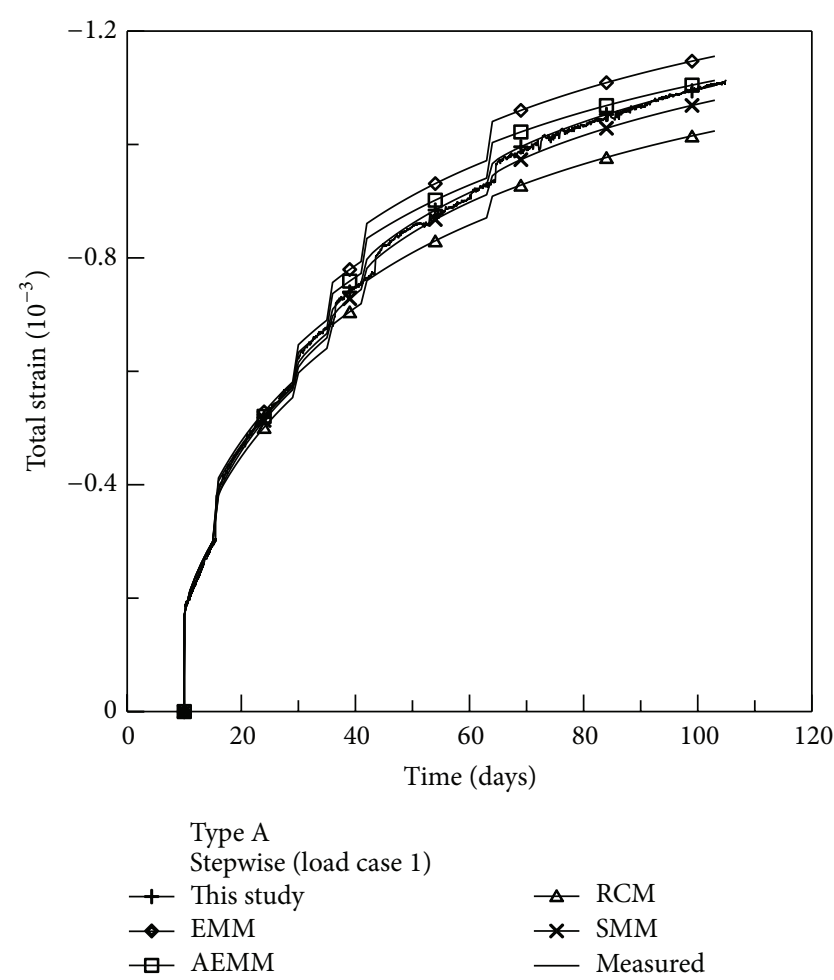

(a)

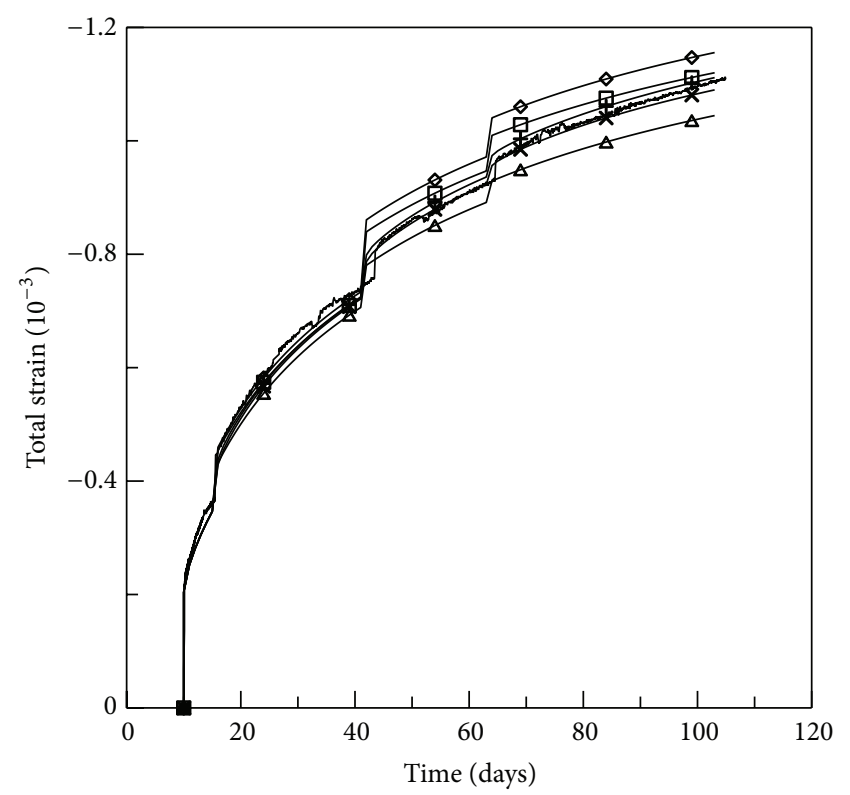

Type A

Stepwise (load case 2)

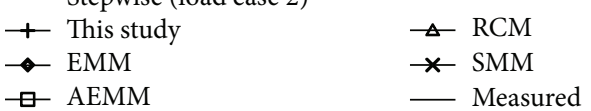

(b)

FIGURE 10: Comparison of the total strain predicted by the five creep models (type A test): (a) load case 1 and (b) load case 2.

at the age of initial loading. Regarding the formulation format, two models, EMM and AEMM, are based on the total format and three models, RCM, SSM, and the presented model, are based on the incremental format.

Figures 10 and 11 compare the total strains predicted by the five creep models for the two stepwise load histories of type A and type B tests, respectively. Figures 10 and 11 show the largest strain for the EMM case among the five creep models. This is because the model uses the values of the modulus of elasticity $E\left(t_{o}\right)$ and creep function $J^{\prime}\left(t, t_{o}\right)$ evaluated at the initial times $t_{o}=10$ days and 7 days for type A and type B tests, respectively, through the entire time period. RCM computes the lowest value of strain, as observed from Figures 10 and 11. The strains predicted by the other three creep models are bounded between EMM and RCM. The strain predicted by AEMM is lower than that predicted by EMM but higher than those by the other three methods. However, this is not an issue in the current numerical prediction because the ageing coefficient value $\chi\left(t, t_{o}\right)$ was set at a constant value of 0.8 through the entire time period. This means that, in this particular creep test program, the value of $\chi\left(t, t_{0}\right)$ may be less than 0.8 . In the cases of EMM, AEMM, and RCM, the value of the elastic modulus was taken as the value evaluated at the initial times of $t_{o}=10$ days and 7 days for type A and type B tests, respectively, while, in the cases of SSM and the presented creep model, a variable value of elastic modulus was used in the analyses. The difference between the two cases is identified in Figures 10 and 11, where a gradual increase of timedependent strain is observed in the latter two methods, while an acute increase of time-dependent strain is observed in the former three methods when the stepwise load was applied.

To investigate the long-term performances of the five models, an axial load of $2 \mathrm{MPa}$ was numerically applied to both of the specimens in type A and type B tests at the ages of 90 days and 103 days, respectively, when the experiments were completed. Strains were computed for 500 days for the five creep models and compared in Figures 12 and 13 for type $\mathrm{A}$ and type $\mathrm{B}$ tests, respectively. In the case of type A test in Figure 12, the strain predicted by the presented model is approximately the same as that predicted by AEMM, and the strain predicted by SSM is lower than both of those. However, the case of type B test in Figure 13 shows that the presented model predicts a strain larger than that of AEMM and SSM. It is noted from the long-term analyses that the AEMM, SSM, and the presented creep models predict creep strains between those of the EMM and RCM models and agree well with each other in the long-term analysis, as well as the short-term analysis.

\section{Conclusions}

A single-curve creep model was presented to depict the creep behavior of concrete subjected to time-varying stress history. The formulation was accomplished by introducing a horizontal parallel creep curve assumption and combining with the vertical parallel creep curve concept of RCM. An ageing factor, defining the effect of concrete age on loading, was 

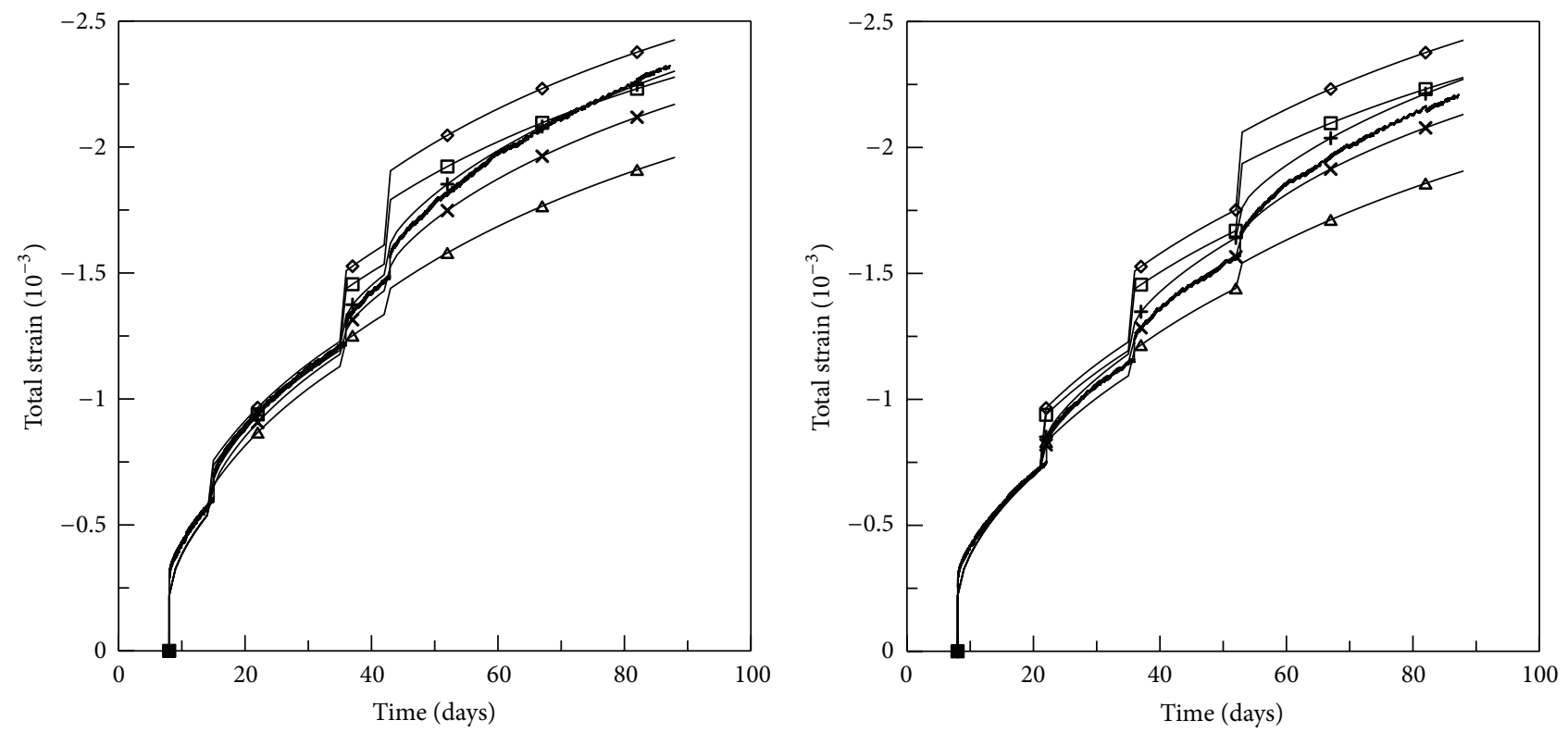

Type B

Stepwise (load case 1)

+ This study

$\rightarrow$ EMM

$\triangle \mathrm{RCM}$

$\rightarrow$ AEMM

$\times$ SSM

— Measured

(a)

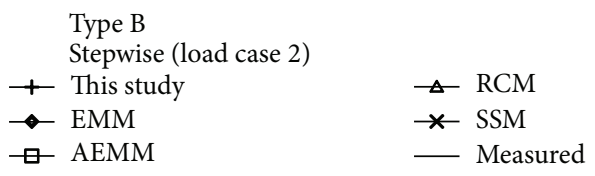

(b)

FIGURE 11: Comparison of the total strains predicted by the five creep models (type B test): (a) load case 1 and (b) load case 2.

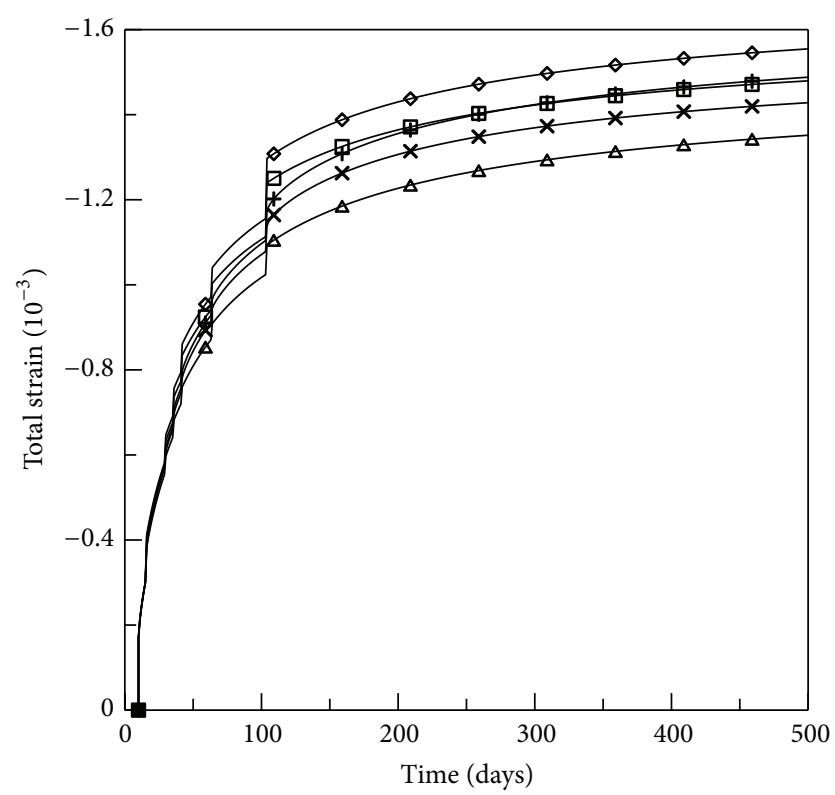

Type A

Stepwise (load case 1)

+ This study

$\rightarrow$ EMM

๑ AEMM

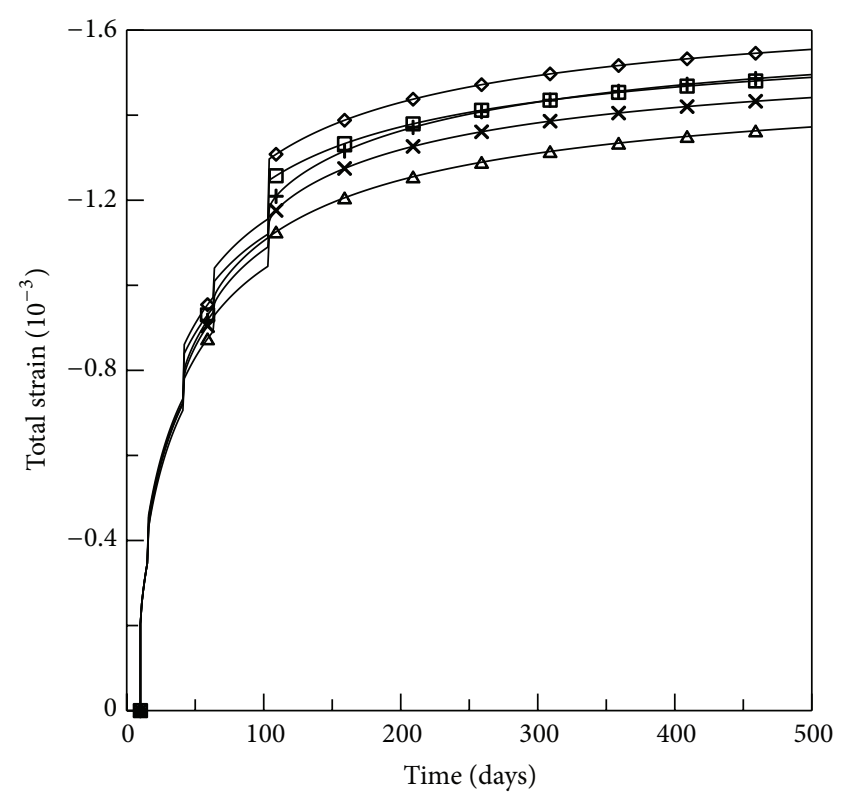

Type A

Stepwise (load case 2)

$$
\begin{aligned}
& + \text { This stud } \\
& \rightarrow \text { EMM } \\
& \square \text { AEMM }
\end{aligned}
$$

(a)

(b)

FIGURE 12: Extended predictions and comparison of the total strain by the five creep models (type A test): (a) load case 1 and (b) load case 2. 

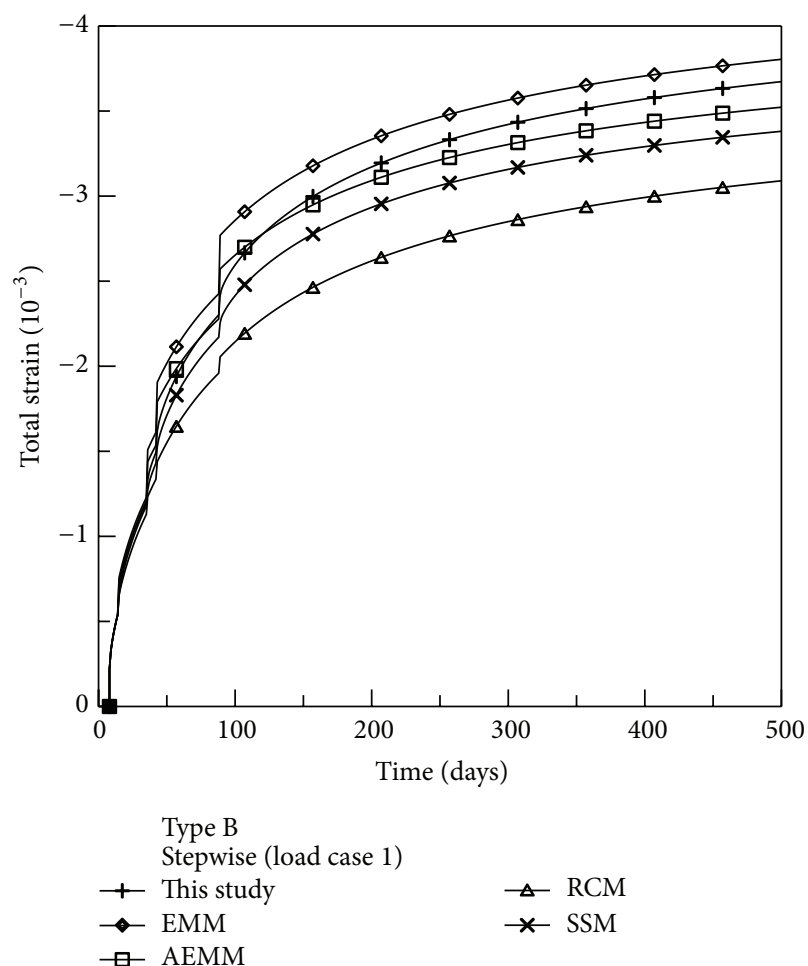

(a)

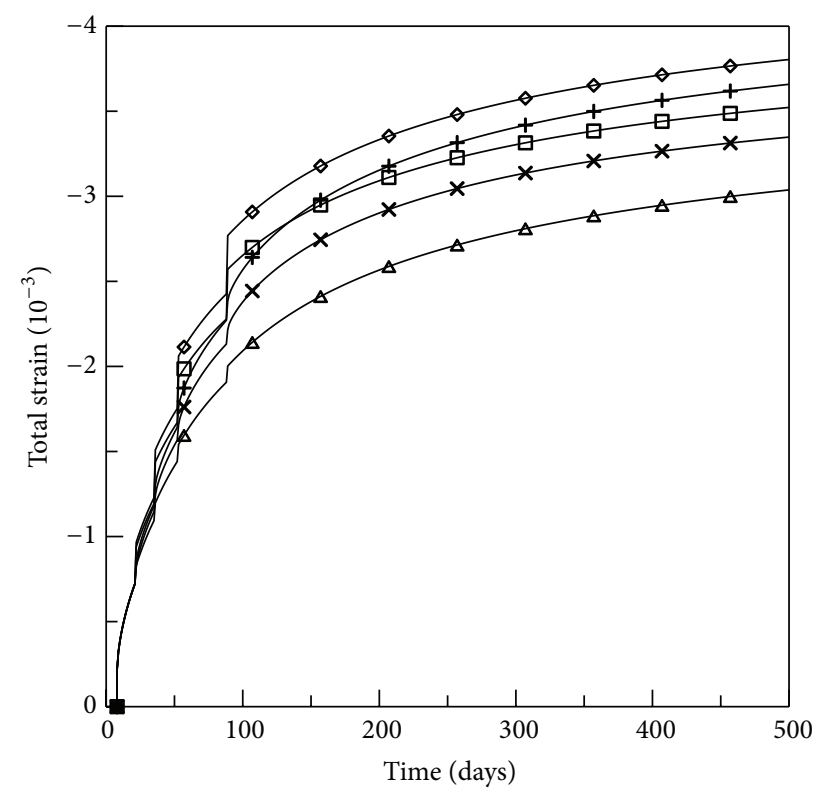

Type B

Stepwise (load case 2)

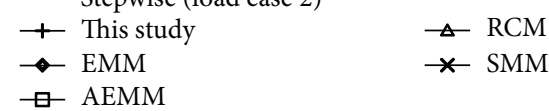

(b)

FIGURE 13: Extended predictions and comparison of the total strain by the five creep models (type B test): (a) load case 1 and (b) load case 2.

introduced to combine the two parallel creep curve concepts. Two sets of laboratory experiments on cylindrical specimens cast with different mixture proportions were conducted to determine the value of the ageing factor. The performance of the presented creep formulation was investigated by comparing the measured strains to the predicted strains and then comparing to the existing four creep models. The following conclusions were drawn:

(1) The presented creep model uses a single creep curve to calculate creep strain under a time-varying stress history. This representation of creep simplifies the age-dependent formulation of the long-term behavior of concrete structures and requires no memory of stress history.

(2) The presented formulation combines the two creep curve concepts that define the upper and lower bounds of creep strain, thereby providing a reliable level of accuracy for the predicted creep strain.

(3) The presented creep model was formulated in an incremental format that allowed accounting for the time-dependent development of the elastic modulus. Furthermore, the incremental form of the presented creep model paves the way for being associated with the incremental form of the time-dependent finite element formulation.

(4) A single value of 0.75 was obtained for the ageing factor through the creep tests under stepwise loads.
The value of the ageing factor indicated that the creep strain is predominantly predicted by the horizontal parallel creep curve assumption, rather than the vertical creep curve assumption, for concrete loaded at a relatively early age.

(5) The predicted strains in the presented creep model were compared to the measured strains and those of the existing four creep models. This indicated that the predicted strains of ageing coefficient method, stepby-step method, and the presented model agreed well with each other and ranged between those of EMM and RCM.

\section{Conflict of Interests}

The authors declare that there is no conflict of interests regarding the publication of this paper.

\section{Acknowledgment}

This work is financially supported by Korea Ministry of Land, Infrastructure and Transport (MOLIT) as "U-City Master and Doctor Course Grant Program.”

\section{References}

[1] F. T. K. Au and X. T. Si, "Accurate time-dependent analysis of concrete bridges considering concrete creep, concrete shrinkage 
and cable relaxation," Engineering Structures, vol. 33, no. 1, pp. 118-126, 2011.

[2] M. A. Chiorino and C. Casalegno, "Evaluation of the structural response to the time-dependent behaviour of concrete: part 1an internationally harmonized format," Indian Concrete Journal, vol. 86, no. 12, pp. 25-36, 2012.

[3] M. F. Granata, P. Margiotta, and M. Arici, "Simplified procedure for evaluating the effects of creep and shrinkage on prestressed concrete girder bridges and the application on European and North American prediction models," Journal of Bridge Engineering, ASCE, vol. 18, no. 12, pp. 1281-1297, 2013.

[4] P. Acker, Z. P. Bažant, J. C. Chern, C. Huet, and F. H. Wittman, "Measurement of time-dependent strains of concrete," Materials and Structures, vol. 31, no. 8, pp. 507-512, 1998.

[5] ACI Committee 209, "Guide for modeling and calculating shrinkage and creep in hardened concrete," ACI 209R-92, ACI, Farmington Hills, Mich, USA, 2008.

[6] A. Al-Manaseer and J.-P. Lam, "Statistical evaluation of shrinkage and creep models," ACI Materials Journal, vol. 102, no. 3, pp. 170-176, 2005.

[7] Z. P. Bazant and J. C. Chern, "Concrete creep at variable humidity: constitutive law and mechanism," Materials and Structures, vol. 18, no. 1, pp. 1-20, 1985.

[8] Z. P. Bazant and S. Bawenja, "Creep and shrinkage prediction model for analysis and design of concrete structures-model B3," Materials and Structures, vol. 28, no. 6, pp. 357-365, 1995.

[9] CEB, "Structural concrete-textbook on behavior, design and performance. Updated knowledge of the CEB/FIP model code 1990," fib Bulletin, vol. 2, pp. 37-52, 1999.

[10] N. J. Gardner and M. J. Lockman, "Design provisions for drying shrinkage and creep of normal strength concrete," ACI Materials Journal, vol. 98, no. 2, pp. 159-167, 2001.

[11] R. I. Gilbert and G. Ranzi, Time-Dependent Behavior of Concrete Structures, Spon Press, 2010.

[12] Z. P. Bažant and F. H. Wittmann, Creep and Shrinkage in Concrete Structure, John Wiley \& Sons, 1982.

[13] A. Ghali, R. Favre, and M. Elbadry, Concrete Structures: Stresses and Deformations, Chapmal and Hall, 1986.

[14] R. I. Gilbert, Time Effects in Concrete Structures, Elsevier Science Publishers, 1988.

[15] M. Jirasek and Z. P. Bažant, Inelastic Analysis of Structures, John Wiley \& Sons, Hoboken, NJ, USA, 2002.

[16] H. Rusch, D. Jungwirth, and H. K. Hilsdorf, Creep and Shrinkage Their Effect on the Behavior of Concrete Structures, Springer, New York, NY, USA, 1983.

[17] W. H. Glanville, "Studies in reinforced concrete-III, the creep or flow of concrete under load," Building Research Technical Paper 12, Department of Scientific and Industrial Research, London, UK, 1930.

[18] O. Faber, "Plastic yield, shrinkage and other problems of concrete and their effects on design," in Minutes of the Proceedings of the Institution of Civil Engineers, vol. 225, part I, pp. 27-73, ICE, London, UK, 1927.

[19] Z. P. Bažant, "Prediction of concrete creep effects using age adjusted affective modulus method," ACI Structural Journal, vol. 69, no. 4, pp. 212-217, 1972. 

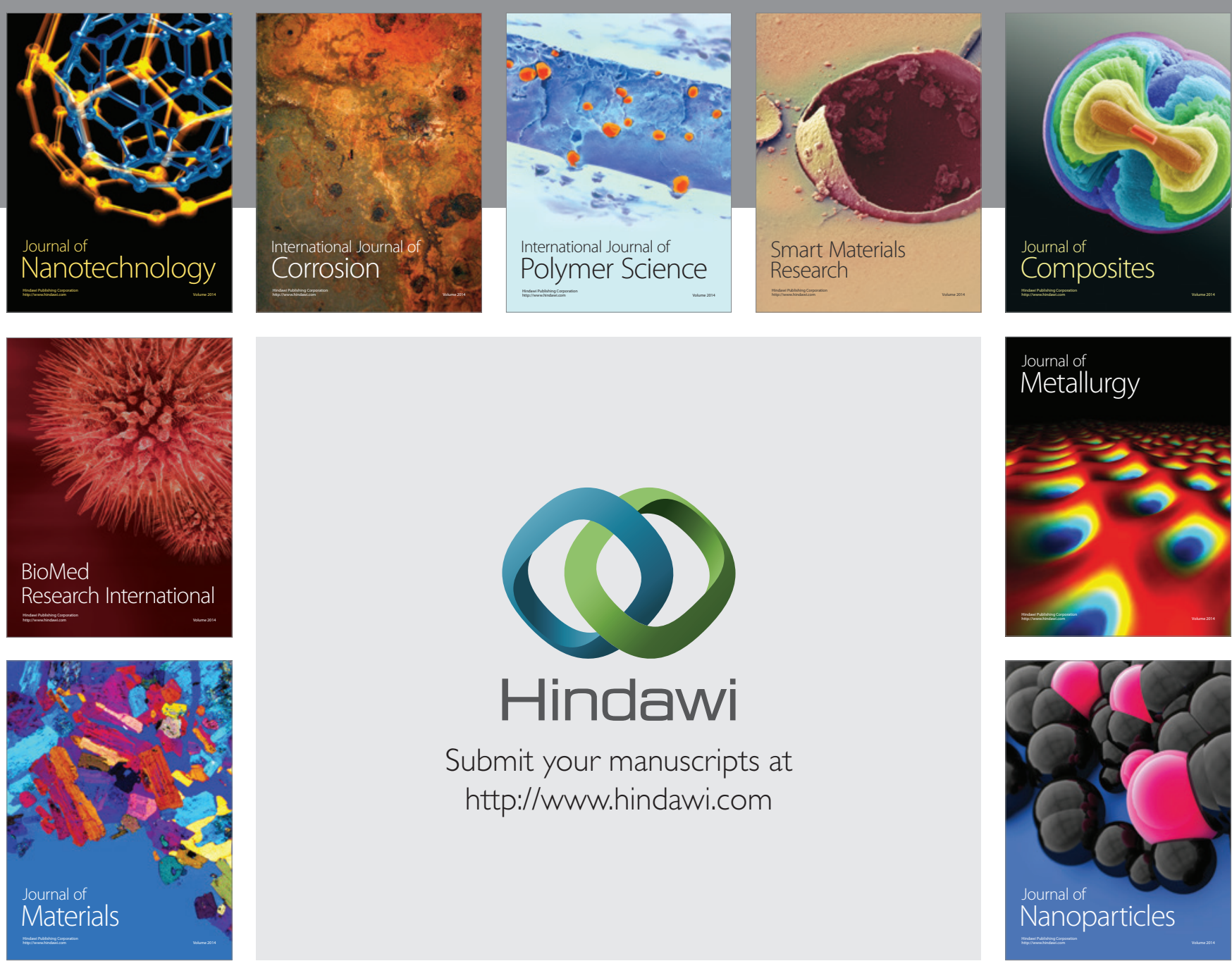

\section{Hindawi}

Submit your manuscripts at

http://www.hindawi.com

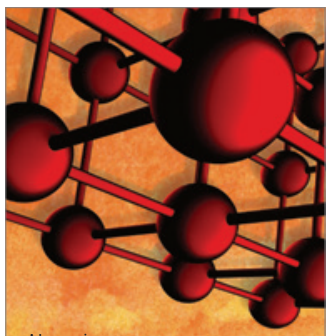

Materials Science and Engineering
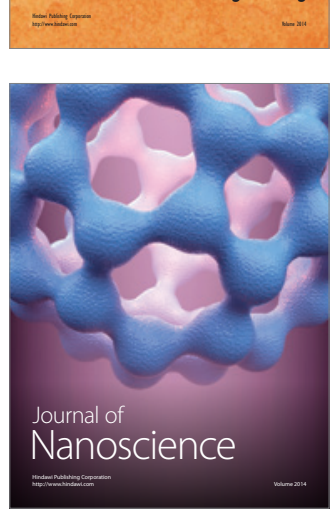
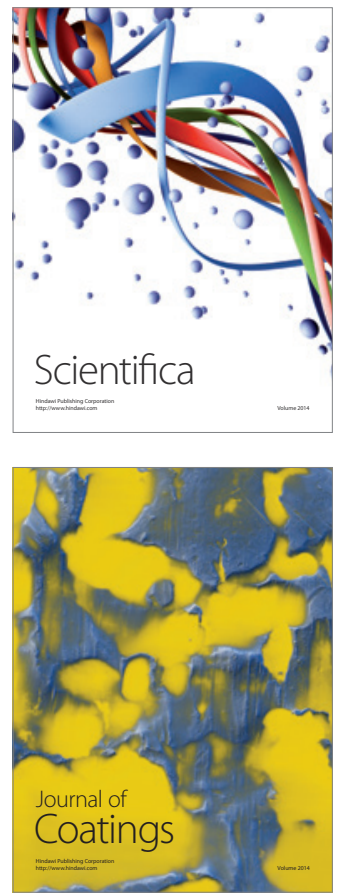
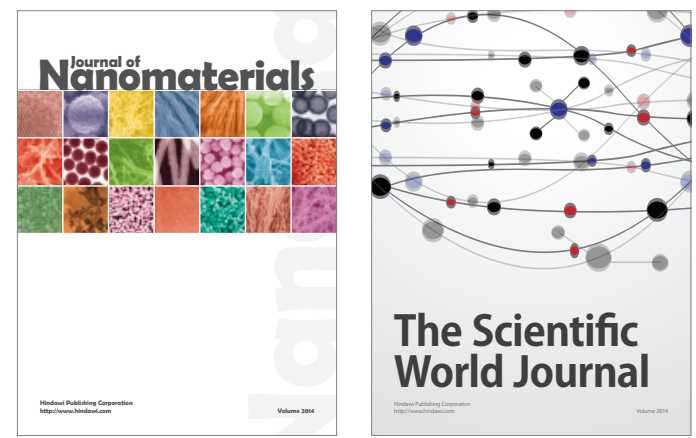

The Scientific World Journal
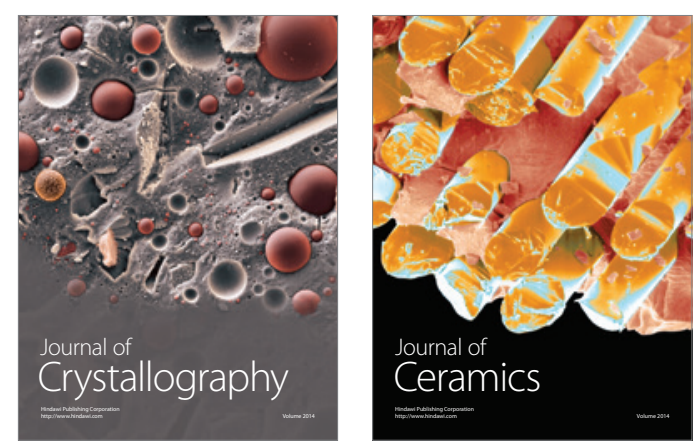
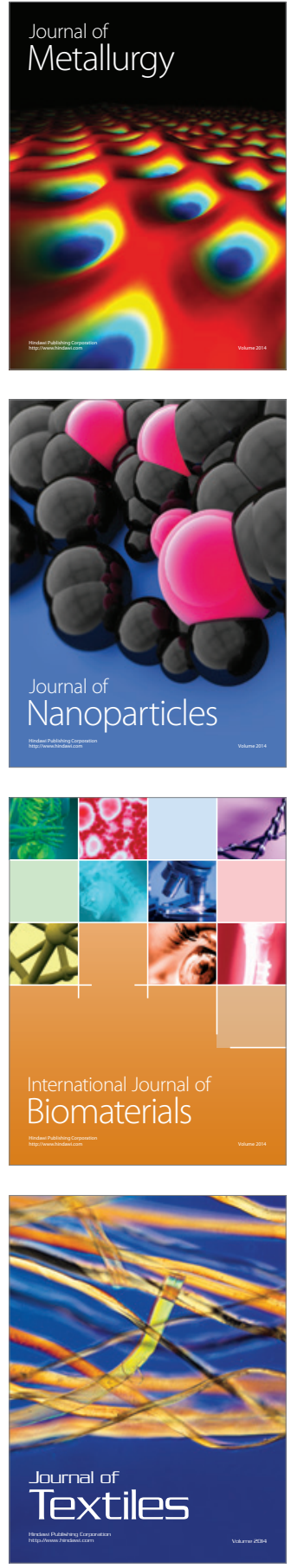